\title{
7 \\ O USO DO SMARTPHONE COMO FERRAMENTA DE ENSINO- APRENDIZAGEM NO CURSO DE MAGISTÉRIO DA ESCOLA ESTADUAL PROFESSORA JUVENÍLIA FERREIRA DOS SANTOS*
}

\author{
Rodrigo Mendonça de Faria
}

\section{Introdução}

A informática foi entrando pouco a pouco na educação, nas escolas norte-americanas se iniciou nos anos 1960, no Brasil as experiências educativas nas escolas e universidades ocorreram na década de 1970. O sentido do uso da tecnologia por meio deda linha teórica e epistemológica, afim de transpor as pesquisas sociais, culturais, históricas e filosóficas, visando o embate entre tecnologia $\mathrm{x}$ pedagogia. Com os avanços dos recursos tecnológicos que acontecem no século XXI, os docentes são pressionados a utilizarem tecnologia nos procedimentos didáticos (FARIA, 2004, p. 57).

Hoje o smartphone é usado para acessar internet, segundo informações do Instituto Brasileiro de Geografia e Estatística (IBGE), que produziu uma cartilha "Características gerais dos domicílios e dos moradores 2017", da Pesquisa Nacional por Amostra de Domicílios (PNAD) Contínua, que traz dados sobre domicílios, em dos levantamento $60,3 \%$ dos brasileiros se conecta na Internet com o smartphone, segundo a pesquisa o smartphone é o equipamento mais utilizado, na frente inclusive dos microcomputadores (IBGE, 2018).

O uso do celular como ferramenta pedagógica ainda não é consensual. A resistência se dá por conta de vários elementos, como a segurança em portar o aparelho na bolsa, o valor do pacote de dados, e, ainda, caso não exista wi-fi no local de trabalho, o fator da dispersão. Smartphone não é obrigatório e o dono investe ou não de acordo com seu interesse ou necessidade de uso. Como ponto negativo, o fator da dispersão da atenção dos discentes especialmente, música, redes sociais, mensagens., atrapalha os docentes em seus trabalhos.

O uso do aparelho não é uma solução definitiva. Hoje, os smartphones são muito utilizados no auxílio de tarefas de casa na relação escolar de ensinoaprendizagem, porém, esta pesquisa se volta para o uso que o professor faz desta tecnologia. Segundo Nagumo e Teles (2016, p. 367), em sua pesquisa "O uso do celular por estudantes na escola: motivos e desdobramentos", "[...] o uso massivo e regular do celular pelos jovens indica que esta inovação já foi

${ }^{*}$ DOI - 10.29388/978-65-86678-49-9-0-f.121-134 
adotada pela maioria das pessoas. Por outro lado, a escola ainda não foi capaz de pensar seus afazeres didáticos com as tecnologias disponíveis.".

Vazquez-Cano e Calvo-Gutierrez (2015) demonstram como o uso adequado de telefones inteligentes (smartphones) no ensino secundário pode ser um recurso educacional com grande funcionalidade para o desenvolvimento dos currículos de assuntos diferentes, para valores de educação e para a promoção de competências básicas; referência fundamental no cenário educacional.

Grande parte dos professores está familiarizada no seu dia-a-dia, com o smartphone, no entanto não se sabe se os professores utilizavam os smartphones em ambientes de ensino. As novas ferramentas tecnológicas reproduzem, na maioria das vezes, o modelo tradicional das escolas. Os smartphones proporcionam facilidades para o dia-a-dia na sala de aula, e os professores que não enxergam nas novas tecnologias da informação e comunicação um instrumento para o processo de ensino-aprendizagem na escola agem conforme explica Freire (1996, p. 66), ignorando a curiosidade intrínseca do educando. Em suas palavras, "[...] o professor que não respeita a curiosidade do educando, o seu gosto estético, a sua inquietude, a sua linguagem, mais precisamente, a sua sintaxe e sua prosódia transgride os princípios fundamentalmente éticos da nossa existência.".

Nossa investigação levou em consideração aspectos particulares, culturais, físicos, econômicos e outros que podem restringir a aquisição de aparelhos celulares. O que torna relevante essa pesquisa levando-se em conta a importância da comunicação na contemporaneidade sem deixar de lado os fatores sociais que devem ser levados em conta. Apresenta-se um olhar holístico, ou seja, busca-se entender o uso do celular pelo professor, que ainda não é totalmente bem-vindo, a resistência se dá por conta de paradigmas, como a segurança em portar o aparelho na bolsa, valor do pacote de dados, caso não exista wi-fi no local de trabalho, além do custo e manutenção do aparelho existe o fator dispersão que o smartphone proporcional.

O que torna relevante este estudo, considerando a importância da comunicação na contemporaneidade, é que trata-se de uma pesquisa cultural no que define se o docente utiliza ou não as possibilidades que o smartphone oferece, tomando como pressuposto epistemológico o estudo da cultura relacionada ao uso do aparelho. Os professores do ensino básico enfrentam cotidianamente dificuldades tecnológicas em seu trabalho, e o smartphone vincula acesso com arquivo de dados, e pode fortalecer as novas tecnologias como ferramentas pedagógicas a serem aplicadas nas escolas, através de um aplicativo que ajuda o professor no uso do smartphone em uma atividade escolar. Esse aplicativo para Android deve ser desenvolvido com base nos dados coletados em pesquisa qualitativa que envolve os pesquisadores mas não é possível ser 
mensurado por equações, mas sim por interpretações. Para Minayo (2007, p. 22), "[...] as ciências sociais em um nível de realidade que não pode ser quantificado, trabalhando com o universo de crenças, valores, significados e outros construtos profundos das relações que não podem ser reduzidos à operacionalização de variáveis.".

A pesquisa compreendeu a atual dinâmica das informações que estão disponíveis na rede mundial de computadores. E levando em consideração que os sujeitos da pesquisa são professores com interesse no uso do smartphone, a fim de utilizar na sala de aula e considerando o uso do aparelho como prática cotidiana, fomentando o uso das tecnologias móveis afim de proporcionar conexão com a internet de maneira prática. O problema da pesquisa foi, portanto, como os professores do Magistério e seus alunos(as), futuros formadores, poderão usar o smartphone como ferramenta pedagógica?

Diante deste contexto em que a Estadual Professora Juvenília Ferreira dos Santos está inserida algumas questões norteiam nosso trabalho:

a) A escola proporciona condições para os professores trabalharem com smartphone?

b) Os(as) professores(as) têm conhecimento para trabalhar com o smartphone como ferramenta pedagógica?

Este estudo potencializa e estimula professores(as) e alunos(as) que atuam no Curso de Magistério o uso dos recursos do smartphone. Prático e relativamente barato (se comparado ao preço de um laptop), o acesso à internet pelo smartphone é rápido e não requer sala fixa. Outra vantagem do aparelho é a de trabalhar com aplicativos que não requerem conexão com internet.

\section{Tecnologias digitais}

Tecnologia digital é um conjunto de tecnologias que permite, principalmente, a transformação de qualquer linguagem ou dado em números, isto é, em zeros e uns $(0$ e 1$)$, como ferramentas pedagógicas.

Em crescente desenvolvimento tecnológico com o surgimento dos computadores de mesa, a vida cotidiana passou para a era da globalização. E constantemente surgem novos avanços modificando nossos modos de comunicar, agir e até mesmo de pensar.

E com a evolução tecnológica surge o primeiro celular, criado em 1974, porém comercializado apenas dez anos mais tarde em uma versão mais compacta e leve. Então na década de 1990 surge o primeiro smartphone, com tela touchscreen. Posteriormente surgem o IPhone em 2007 e o projeto Androide (sistema operacional de código aberto para smartphones) da Google. 
Atualmente, o smartphone pode ter mais utilidade que os computadores, já que as suas ferramentas podem ser de grande utilidade para solucionar a escassez de recurso tecnológico e para o desenvolvimento de planos de ensino que contem com materiais na rede virtual, conforme exposto por Veen e Wrakking, (2009, p. 175): "[...] a escola, sendo meio para sistematização da educação e da aprendizagem, deve atender aos interesses e às necessidades da sociedade, entre esses: a necessidade de acompanhar ou preconizar as tecnologias inerentes aos avanços da sociedade.".

Então, por que não trabalhar com as tecnologias digitais na escola? Ao analisar o uso do aparelho celular na vida contemporânea nota-se que o smartphone é a ferramenta que propicia a conexão, mas prática e rápida.

Desenvolver estratégias interdisciplinares que estimulem o interesse dos pesquisadores, docentes e discentes é o fundamento para criação de ferramentas pedagógicas contemporâneas. A Fundação de Amparo à Pesquisa de Minas Gerais (Fapemig), agência pública de fomento, é uma das raras fundações de empresas privadas, apoiam soluções criativas para a constante atualização com as Tecnologias Digitais (FAPEMIG, 2018).

São indiscutíveis as novas tecnologias inseridas na sociedade, principalmente no que diz respeito à interação humana por meio do smartphone. Muitos aplicativos foram desenvolvidos exclusivamente para uso em aparelhos celulares nos últimos anos gerando mudanças comportamentais e de paradigmas.

É prático baixar pela internet aplicativos voltados para educação infantil, porém sua limitação e bloqueios, para realizar modificações de conteúdo limita seu uso outro problema são as propagandas reproduzidas no aplicativo. Os professores(as) como transmissor de tecnologia devem usar e dominar noções mínimas de programação para planejar suas aulas, já que são muitas as funções que os fabricantes de smartphone incorporam no aparelho, conexão com hipertexto, registro de imagens, localização, banco de dados que podem ser trabalhados em sala, transformando a escola em um local que trabalha com inovação, investigando as novas tecnologias.

\section{A Escola}

Esta pesquisa justificou-se pela quebra de paradigmas que propõe no processo fundamental de ensino-aprendizagem escolar, com professores do magistério, ou seja, formadores de formadores, tomando como foco central a potencialização ao estímulo e resposta da aprendizagem dos professores(as) e alunos(as) do magistério com o uso do smartphone como ferramenta pedagógica. Assim, criando oportunidade para o uso dos recursos disponibilizados no aparelho smartphone, também, utilizar como ferramenta didática para tentar resolver a falta de estrutura tecnológica nas escolas. 
Neste sentido, a pesquisa apresentou várias oportunidades de trabalhar em espaços escolares e não escolares, a fim de facilitar a aprendizagem de formadores em diferentes fases do desenvolvimento humano ao encontro de novas atualizações no processo educativo desses sujeitos. A pesquisa trata de uma investigação que foi realizada na Escola Estadual Professora Juvenília Ferreira dos Santos, esta possui formação de professores do Magistério, que tem como objetivo formar profissionais para atuarem na educação infantil. A referida escola iniciou o Curso Normal de Nível Médio no Estado, (curso de Magistério) no segundo semestre de 2015, começou ofertando 160 vagas. O curso tem duração de um ano e meio, assim explicou o diretor Wesley Rodrigues ao jornal Correio de Uberlândia.

A escola de ensino fundamental situada em Uberlândia, Minas Gerais, na Rua Antônio Rufino Borges, 325 no bairro Luizote de Freitas, foi criado inicialmente para atender a comunidade, com constante crescimento econômico e de renda na região, atualmente tem papel importante na geração de profissionais da educação.

De acordo com dados divulgados pelo IBGE, em 2010, o bairro apresentava uma população de 19.168 habitantes, integrado no setor oeste da cidade (UBERLÂNDIA, 2010), atualmente é bairro apresenta forte comércio, sendo que dispõem de várias instituições públicas, como bancos, agências e comércio afirmando o desenvolvimento do Bairro e consequentemente da escola.

Portanto, esta pesquisa está relacionada aos estudos da cultura contemporânea e da educação, com foco no uso do smartphone. Como fundamentação teórica para esta investigação, considera-se a importância da comunicação na contemporaneidade, argumento que torna relevante o estudo. Os professores do ensino técnico/magistério enfrentam cotidianamente dificuldades tecnológicas em seu trabalho e o smartphone vincula acesso com arquivo de dados, o aparelho pode fortalecer as novas tecnologias como ferramentas pedagógicas a serem aplicadas nas escolas.

\section{Aspectos metodológicos}

A consulta bibliográfica sobre o objeto teórico e metodológico da pesquisa vem sendo executada desde o início do mestrado e figura, em grande medida, ao longo da dissertação. Por este ângulo, "[...] a pesquisa bibliográfica é um apanhado sobre os principais trabalhos científicos já realizados sobre o tema escolhido e que são revestidos de importância por serem capazes de fornecer dados atuais e relevantes", como contam Boni e Quaresma (2005, p. 71). 
Este tipo de pesquisa abrange publicações avulsas, livros, jornais, revistas, músicas, vídeos e é tão importante quanto as metodologias direcionadas ao trabalho de campo, pois amadureceu a visão do pesquisador sobre as suas questões de pesquisa, colocando-o, em certa medida, em interlocução com outros pesquisadores da área e da temática.

É fato que muitos são os professores que não possuem orientações e estudos sobre as possíveis práticas pedagógicas que consideram o uso do smartphone. Especificamente no que diz respeito a programação para iniciantes, softwares facilitadores que funcionam sem estarem atrelados a códigos pagos. São muitos os trabalhos que podem ser realizados com o uso do smartphone e a proposta de produto desta pesquisa configura-se, apenas, como um dos possíveis desenvolvimentos da utilização do smartphone.

Para isso, foi realizada uma reflexão sobre o uso e interação dos professores com os smartphones, pensado em como seria possível os professores utilizar o smartphone no processo ensino-aprendizagem. Com base nesses dados coletados entre professores por meio deste estudo, foi produzido um aplicativo livre para uso do smartphone em sala de aula e em ambiente não escolar.

Realizou-se uma oficina de capacitação para os professores do Magistério e a criação de um produto, desenvolvido para aplicação nas escolas, com o intuito de subsidiar os profissionais da educação para o uso do smartphone como ferramenta pedagógica. Foram considerados os aspectos sociais, culturais, históricos, políticos e filosóficos para que os profissionais da educação pudessem compreender, planejar e organizar sua prática docente na Educação Básica.

O desenvolvimento de aplicativo, produto desta pesquisa, o trata como um material didático. Criado com base nos dados coletados na etapa de pesquisa qualitativa, servindo como um suporte pedagógico ao professor no uso do smartphone em atividade escolar.

Foram incluídos no projeto os professores do curso de Magistério da Escola Juvenilia, e que concordaram em participar da pesquisa assinando o Termo de Consentimento Livre Esclarecido (Anexo A) e preenchendo o questionário (Anexo B).

Foram excluídos do projeto os professores que não concordaram em participar da pesquisa.

A proposta foi analisar e entender como os smartphones têm sido utilizados pelos professores no âmbito do ensino básico. Verificou-se como os recursos do smartphone podem contribuir com o processo ensino aprendizagem em sala de aula, compreendendo-os como uma solução tecnológica que possa ajudar o docente a potencializar a aprendizagem. 
No que se refere a metodologia do trabalho este foi viável pois propôs orientações aos docentes se tornando um material didático de baixo custo e de grande valia para a indústria tecnológica, o mercado lança novos smartphones cada vez com mais recursos, e estes aparelhos podem contribuir no processo de ensino.

Em consonância ao disposto em legislação vigente, o projeto desta pesquisa foi submetido a apreciação do Comitê de Ética e Pesquisa (CEP) da UNIUBE e aprovado.

\section{Resultados}

O questionário composto por 24 perguntas, sendo as seis primeiras perguntas sobre informações pessoais, para identificação do perfil do professor, e as restantes (18) intentam a entender a utilização da tecnologia smartphone por esses indivíduos: se possuem acesso, bem como se levam esse aparelho para a sala de aula. Foram feitas perguntas sobre a instituição que trabalham, para definir o nível de acesso desse professor à internet e se a escola oferece recursos tecnológicos suficientes. Foi também questionado sobre o uso do smartphone dentro e fora da instituição onde trabalha e o tipo de acesso que utiliza, se acessa ou não a internet em seu local de trabalho. O professor responde, ainda, se acredita no uso das novas tecnologias em sala de aula e se já as utilizou para fins didáticos. E, por fim, o questionário trata sobre o que o professor acredita ser mais didático para orientação do uso do smartphone em sala de aula.

Com a análise dos questionários aplicados em junho de 2018, cinco professores responderam ao questionário, destes quatro são do sexo feminino e um do sexo masculino.

A maioria dos entrevistados tem idade entre 40 e 50 anos, sendo que: três professores possuem de 40 a 50 anos, um professor possui de 30 a 40 anos e uma professora tem de 50 a 60 anos. Apresentavam um tempo de experiência em sala de aula diversificado, sendo que uma professora trabalha como docente de zero a cinco anos, dois professores de seis a dez anos, e duas professoras há mais de 20 anos;

Todos os entrevistados atuam no Ensino Médio e apenas um dentre eles atua no Ensino Fundamental também. Todos os entrevistados possuem pósgraduação, destes quatro deles possuem Especialização e um é mestre.

Três professores trabalham em apenas uma escola e dois deles em duas. Todos os entrevistados possuem de 100 a 150 alunos e um deles possui número elevado a este. Todos os entrevistados participaram nos últimos cinco anos de cursos, oficinas, seminários ou congressos.

Ao analisar a relação dos professores com a internet e os smartphones observou-se que quanto a finalidade, os recursos tecnológicos servem para 
projetar slides, DVD ou vídeos, consultar a internet e estabelecer comunicação interna (e-mail, redes sociais).

No que se refere ao conhecimento dos entrevistados sobre sistemas como MS-DOS, Windows e Android, identificou-se que possuem conhecimento básico de todos.

Quando perguntados há quanto tempo possuíam smartphones, a maioria respondeu que há mais de quatro anos. Apenas uma entrevistada possui o aparelho há um ano. Quatro dos cinco entrevistados acessam a internet pelo smartphone quando estão na escola. A maioria dos entrevistados utilizam o smartphones como ferramenta pedagógica para um melhor aprendizado dos alunos. Três dos entrevistados acreditam que a escola deva opinar no uso de aparelhos eletrônicos pessoais pelos professores em sala de aula. Dois deles não acreditam nisso. Todos os entrevistados já utilizaram seu aparelho móvel pessoal em sala de aula para fins didáticos.

O smartphone e notebook figuram entre os aparelhos mais utilizados pelos professores em sala de aula todos os entrevistados possuem planos pré-pago ou pós-pago de acesso à internet. A maioria dos entrevistados utiliza o wi-fi da escola. Figuram entre os sites e aplicativos utilizados em sala de aula: e-mails, buscadores, Youtube, Google Tradutor e Google Maps.

Todos os entrevistados acreditam que a tecnologia em sala de aula pode despertar maior interesse dos alunos.

A primeira parte do processo de Criação de aplicativos para celular foi realizada em parceria com a coordenação do Curso de Magistério, organizado no sábado as 14 horas. O pré-requisito para participar do curso foi que os participantes tenham conta Google, smartphone android e que seja servidor ou discente da escola. O curso foi dividido em três módulos. O primeiro momento foi uma mesa redonda sobre educação infantil, onde discutiu-se sobre a importância da capacitação dos educadores.

$\mathrm{Na}$ segunda parte, foi realizado o curso com os equipamentos do Laboratório de Informática da escola. Na oportunidade, os participantes se conectaram em sua conta de e-mail e foi apresentado a meta do curso: criação de um aplicativo relacionado à educação infantil.

$\mathrm{Na}$ sequência, foram iniciados os primeiros movimentos em programação, em blocos.

A alternativa encontrada para iniciar os formadores em programação foi o MIT App Inventor, site que conta com ajuda do Instituto de Tecnologia de Massachusetts (MIT) disponibiliza em sua plataforma on-line, programação por meio de encaixe em blocos, ideal para demonstrar os recursos e funcionalidades que o smartphone pode oferecer como ferramenta de aprendizagem. 
Possibilidade de planejar, iniciar e criar aplicativos para smartphone de forma simples e intuitiva, com um grande diferencial, o site traduzir seu arranjo e funções para português do Brasil, principalmente os nomes das ferramentas disponíveis, facilitando utilizar os recursos do smartphone, como a memória, galeria de fotos, GPS, conexão com internet, ou seja, as funções do smartphone.

Oferecer a possibilidade de criar aplicativos totalmente funcionais em pouco tempo e sem custo, o MIT App Inventor ${ }^{1}$ e não requer instalação de programas em seu sistema, destaque para sua missão de oferecer um primeiro aplicativo simples instalado e funcionando em menos de 30 minutos, uma ferramenta baseada em blocos de encaixe que facilita a criação de aplicativos complexos e de alto impacto em um tempo significativamente menor do que os ambientes de programação tradicionais. "O projeto MIT App Inventor busca democratizar o desenvolvimento de software, capacitando todas as pessoas, especialmente os jovens, para passar do consumo de tecnologia para a criação de tecnologia." (MIT APP INVENTOR, 2017, s/p).

Durante o curso foi discutido temas como o código aberto, refletiu-se sobre o uso e interação dos professores com os smartphone, e surgiram questões que permitiram discutir a importância do Software Livre, e suas quatro liberdades essenciais ${ }^{2}$, segundo a Free Software Foundation (FSF), que é uma organização sem fins lucrativos, segundo informações de seu site oficial, com a missão de promover a liberdade de usuários de computador.

Um dos motivos reais do professor criar um aplicativo é a não veiculação de propaganda na tela do smartphone, a possibilidade de melhorar o aplicativo podendo adaptar para a necessidade a aula. Outro aspecto positivo que merece destaque é a liberdade de distribuir para os alunos(as), o docente é transmissor de tecnologia e integrante ativo no processo criativo.

Após a oficina, ocorreu o terceiro momento da oficina, onde foram abordadas outras possibilidades de aplicação do smartphone e o futuro da profissão docente (Figura 6), em um clima de descontração e socialização.

Em consenso, os participantes da oficina gostaram do curso e sugeriram novos módulos, como a aplicação do Mit App inventor para criação de livros, provas de múltipla escolha que podem ajudar os formadores em atividades dentro e fora da escola. Os participantes com pacote de dados que enviaram o .apk (programa) para sua conta de e-mail, conseguiram visualizar o aplicativo desenvolvido no curso funcionando em seu smartphone.

$\mathrm{Na}$ sequência, é apresentada uma atividade a ser desenvolvida com os alunos por meio do aplicativo desenvolvido na oficina de capacitação. Os professores sugerem, por meio de registro de uma folha, a elaboração de uma redação temática sobre um local de sua região. Nesta folha haverá um endereço

\footnotetext{
${ }^{1}$ Cf. http://appinventor.mit.edu/explore/.

${ }^{2}$ Cf. http://www.gnu.org/philosophy/free-sw.html.
} 
eletrônico, caso o aluno tenha um smartphone, ele poderá ser orientado a fazer o download do aplicativo Uniube (Figura 1) produto desta pesquisa. Após a produção da redação, tendo o aluno já instalado o aplicativo, ele poderá produzir fotos ou vídeos (Figura 2), por meio dos recursos da câmera do smartphone, no intuito de "ilustrar a redação"

Figura 1 - Tela inicial do aplicativo

\begin{tabular}{|l|l|}
\hline Rodrigo Faria & \\
\hline & FOTO \\
\hline VÍDEO \\
REDAÇÃO \\
\hline escreva aqui \\
SALVAR \\
\hline
\end{tabular}
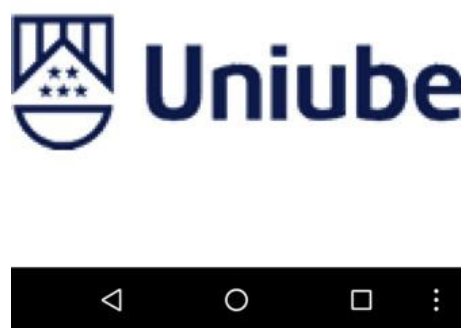

Fonte: Arquivo do autor.
Figura 2 - Recurso de fotografia do aplicativo

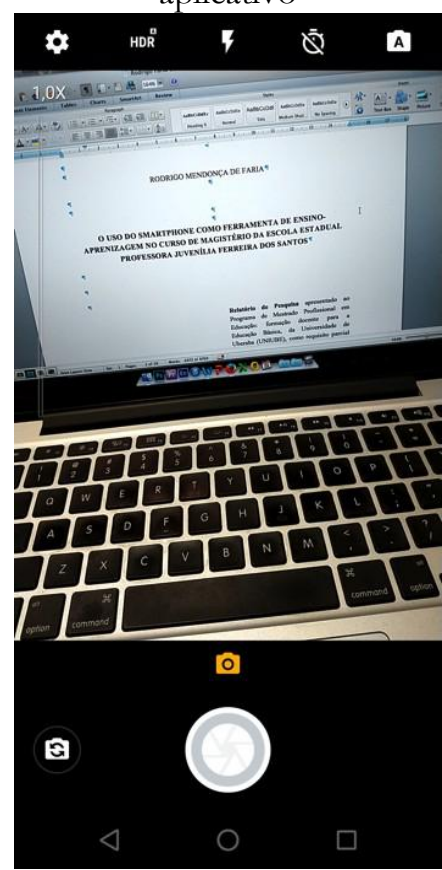

Fonte: Arquivo do autor.

Após produção imagética, o aluno ainda contará com um campo de preenchimento para que digite texto (Figura 3). 


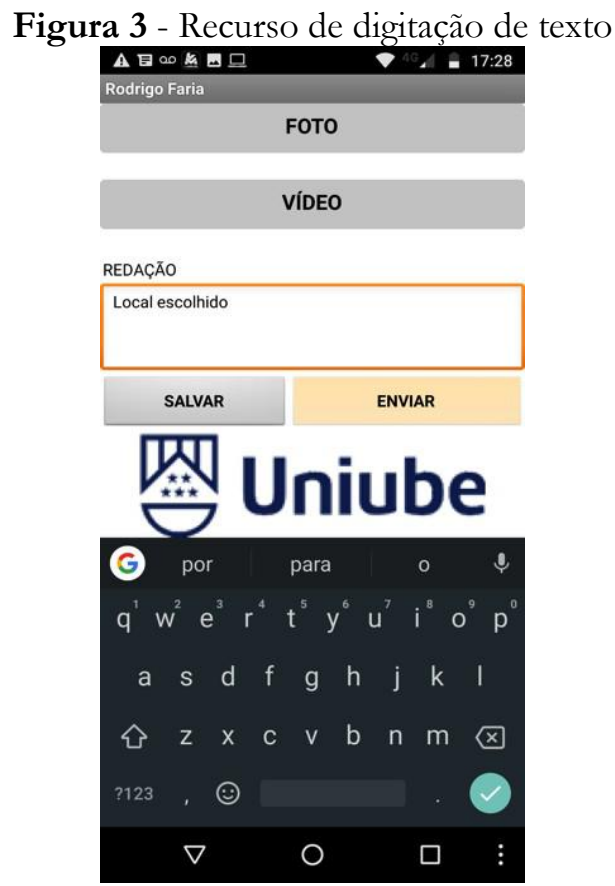

Fonte: Arquivo do autor.

O texto digitado e a imagem produzida poderão ser enviados diretamente para o e-mail do professor, com a localização geográfica registrada pelo smartphone.

Tendo desenvolvido o processo de capacitação com os professores, cabe agora, propormos uma atividade pedagógica, que será conduzida a partir do nosso aplicativo, para uso do smartphone no contexto educativo. Foi produzido um aplicativo que propõe o uso do smartphone no ambiente escolar e não-escolar, produto desta pesquisa de mestrado e através dos resultados do questionário aplicado aos docentes do Curso Normal, foi possível projetar as contribuições do produto para a carreira do professor, colaborando no equacionamento do problema da pesquisa e de propostas de ações que auxiliem os envolvidos a ampliar o conhecimento e socializá-lo com a coletividade.

No aplicativo desenvolvido para o sistema android destacam-se alguns dos recursos que podem ser utilizados no smartphone, como a comunicação rápida, quando existe acesso à internet entre docente e discente, registro audiovisual, criação de texto e localização geográfica. Para que o aplicativo, seja utilizado nas aulas é extremamente necessário que o professor esteja sintonizado com as novas ferramentas didáticas, dominando suas funções para 
alcançar vários objetivos institucionais nas atividades de ensino. Neste sentido, Kenski (2012) lembra a relevância de se decidir sobre qual nova tecnologia utilizar e complementa que devem ser ações definidas rapidamente. "São exigidas também novas formas de decisão, mais rápidas e menos burocráticas, garantindo maior autonomia aos departamentos e às áreas específicas da instituição para tomarem decisões na velocidade requerida pelas redes." (KENSKI, 2012, p. 80).

Este trabalho teve valor acadêmico e teórico-prático pois destacou as vantagens da utilização do smartphone, que são pequenos processadores de informação que melhoram a eficiência, gera conexão a informações $\mathrm{e}$ aplicativos proporcionado variedade de conteúdo no ambiente escolar e não escolar. Sibilia (2012), diz que enquanto os alunos de hoje vivem fundidos com diversos dispositivos eletrônicos e digitais, a escola continua obstinadamente arraigada em seus métodos e linguagens analógicos; isso talvez explique por que os dois não entendem e as coisas já não funcionam como se esperaria.

\section{Considerações Finais}

Tensionamento diz respeito a dificuldade de aceitação das novas tecnologias crescentes na sociedade contemporânea que reflete no entendimento de vida das crianças e consequentemente no ambiente escolar, é um processo educativo que se estabelece no ensino aprendizagem professor e aluno. O conhecimento no cotidiano do professor e aluno, sobre os saberes científicos no saber escolar e a problematização da tecnologia. A temporalidade entendida aqui como movimento de produção de sentido. Smartphones estão presentes nas instituições de ensino e os educadores podem tirar proveito deste fato. Temos conexão rápida, acesso a dados, fotos, modelos, porém o professor não recebeu em sua formação conhecimentos teóricos para utilizar as ferramentas de comunicação, e nem adiantaria, pois a atualização precisa ser constante e permanente a cada novo semestre.

Em relação ao uso de tecnologia, esse é bem visto pelos educadores, pois configuram o dia-a-dia da vivência escolar, inovando os processos de formação e aperfeiçoamento docentes, a prática pedagógica das instituições de ensino, especialmente o professor e o seu trabalho docente cotidiano. Deixando claro que falar em aprimoramento docente significa considerar questões relativas tanto aos estudos sobre o processo de ensino e a formação do professor. Quanto aos estudos sobre a contemporaneidade relacionando com uso das novas tecnologias, foram apontados com destaque na pesquisa, como gargalo à ser resolvido, qual melhor maneira de capacitar o formador visando o alcance da prática docente que potencializa a função social de transmitir o conhecimento. 
Capacitar é, com certeza, o caminho para o professor se firmar como sujeito educador que consegue organizar os pensamentos de seus alunos em uma rede com milhões de informações, usar tecnologias digitais é fundamental, conhecer e dominar o produto desta pesquisa é relevante, porém, é no recurso humano que está a verdadeira mudança, os investimentos em educação devem priorizar a capacitação docente de forma rápida e sem burocracia.

\section{Referências}

BONI, V.; QUARESMA, S. J. Aprendendo a entrevistar: como fazer entrevistas em Ciências Sociais. Revista Eletrônica dos Pós-Graduandos em Sociologia Política da UFSC, Florianópolis, v. 2, n. 1, p. 68-80, jan./jul. 2005. Disponível em:

https://periodicos.ufsc.br/index.php/emtese/article/viewFile/\%2018027/169 76. Acesso em: 9 out. 2017.

FARIA, E. O professor e as novas tecnologias. In: ENRICONE, D. (org.). Ser professor. 4. ed. Porto Alegre: EDIPUCRS, 2004. p. 57-72.

FARIA, E. Pedagogia da autonomia: saberes necessários à prática educativa. São Paulo: Paz e Terra, 1996.

FUNDAÇÃO DE AMPARO À PESQUISA DO ESTADO DE MINAS GERAIS. Inovação tecnológica. Disponível em: http://www.fapemig.br/inovacao-tecnologica. Acesso em: 7 jul. 2018.

IBGE. Características gerais dos domicílios e dos moradores 2017. Ed. IBGE. Coordenação de Trabalho e Rendimento. Rio de Janeiro, 2018

IBGE. Tecnologias e ensino presencial e a distância. 9. ed. Campinas: Papirus, 2012.

MINAYO, M. C. de S. O desafio do conhecimento: pesquisa qualitativa em saúde. 10. ed. São Paulo: Hucitec, 2007.

MIT APP INVENTOR. Sobre nós. 2017. Massachusetts Institute of Technology. Disponível em: http://appinventor.mit.edu/explore/. Acesso em: 7 jul. 2018.

NAGUMO, E.; TELES, L. F. O uso do celular por estudantes na escola: motivos e desdobramentos. Revista Brasileira de Estudos Pedagógicos, Brasília, v. 97, n. 246, p. 356-371, ago. 2016. Disponível em: http://www.scielo.br/scielo.php?script=sci_arttext\&pid=S217666812016000200356\&lng=en\&nrm=iso. Acesso em: 25 set. 2017. 
SIBILIANA, P. Redes ou paredes: a escola em tempos de dispersão. Trad. Vera Ribeiro. Rio de Janeiro: Contraponto, 2012.

UBERLÂNDIA. Prefeitura Municipal de Uberlândia.. População por bairro. Uberlândia. Secretaria Municipal de Planejamento Urbano. Diretoria de Pesquisas Integradas. 2010. Disponível em:

http://www.uberlandia.mg.gov.br/uploads/cms_b_arquivos/1460.pdf. Acesso em: 25 set. 2017.

VAZQUEZ-CANO, E.; CALVO-GUTIERREZ, E. Adolescentes y cibermedios. Una didáctica basada en aplicaciones periodísticas para

smartphones. Estudios Pedagógicos, Valdivia, v. 41, n. 2, p. 255-270, 2015. Disponível em: http:/ /www.scielo.cl/scielo.php?

script $=$ sci_arttext\&pid $=$ S0718-07052015000200015\&lng $=$ es\&nrm $=$ iso. Acesso em: 25 set. 2017.

VEEN, W.; VRAKKING, B. Homo Zappiens: educando na era digital. Trad. Vinícius Figueira. Porto Alegre: Artmed, 2009. 